\title{
Correspondence
}

\section{The future of the BPA}

Sir,

I have read Dr Forfar's personal paper with sadness and surprise. His view of the story of paediatrics and the Royal Colleges of Physicians, at least as far as this College is concerned, is based on misunderstanding and misinformation. The statements that the Joint Paediatric Committee was 'not allowed to develop', and that ultimate authority is 'vested in committees controlled by physicians concerned with adults' are simply erroneous. Authority in this College lies with Comitia to which all Fellows have full access. Also untrue is the statement that unlike the democratic BPA, the College and Comitia of this College have not had full opportunity to discuss the situation. Dr Forfar was on the Council of this College and if he thought our discussions on these issues were inadequate he could easily have enlarged them.

Let me summarise the position of this College with regard to the future of paediatrics. We support the aims of the BPA and are as concerned as they are with the future of paediatrics. We believe that it should lie within the general body of medicine, not in a separate College which we think would divide and weaken paediatrics and general medicine. We explained this to Dr Forfar, then President, and Dr T L Chambers, the Secretary of the BPA, when they came to see College Officers a couple of years ago. We said that the College would, however, welcome a suggestion of a Joint Faculty and do all we could to help it forward. Dr Forfar seemed at the time to welcome these views. We did not take any initiative thereafter as clearly that lay with the paediatricians - if we had done so we might well have been accused of interfering in the affairs of the BPA. Indeed, the College has had no proposal from the BPA until recently, after Dr Forfar wrote his article, when the present President of the BPA wrote to the President.

The position of paediatrics in this College at present is that there is always a paediatric censor, one of the three representatives on the Joint Consultants' Committee is a paediatrician and, in response to a BPA initiative, we have now created paediatric Regional Advisers who had their first meeting in October.

We were under the impression that we had met all the paediatricians' requests and are at a loss to understand $\mathrm{Dr}$ Forfar's evident sense of grievance.

We are anxious to find a way forward that will be in the interest of children and their doctors, and which will keep paediatrics and general medicine as closely together as possible.

D A PyKe

Registrar,

Royal College of Physicians,

11 St Andrew's Place, London NWI 4LE

\section{Inner city tuberculosis and immunisation policy}

Sir,

I read with interest the article by Cundall and Pearson on neonatal BCG immunisation. ${ }^{1}$ Although I applaud their conclusion that poverty may be a better indicator than ethnic origin of the risk of contracting tuberculosis I fear that this conclusion is based on a misleading analysis of their data. They tell us that it is policy (with an $86 \%$ uptake) in Leeds to immunise Asian children with BCG. Therefore they are comparing immunised Asian children with unprotected white children. If one calculates a rate for Asian children who are not vaccinated (910 children) it comes to an annual rate of 44 cases per 100000 compared with their rate for white children of 5.5 (assuming that BCG is $100 \%$ effective). Taking their lower quoted figure for protection of $64 \%$ this leaves a total unprotected Asian population of 2922 and therefore an annual rate of 13.7 cases per 100000 . This is still 2.5 times greater than the rate for white children. A similar calculation (assuming $64 \%$ protection) results in a rate of 10.7 (their rate 10.0 ) for the urban priority area and 3.9 (their rate 3.9 ) for the non-urban priority area.

I would suggest that this analysis of their figures, which although crude does attempt to compare unprotected Asian and white children, supports the conclusion that immunising Asian children at birth reduces the incidence of tuberculosis in that group but does not support their conclusion that poverty is a better indicator than ethnic group of the risk of tuberculosis in childhood (Asian rate 13.7, urban priority area rate 10.7). These figures still support the idea that an expansion of neonatal BCG immunisation to include all children from the more disadvantaged areas is worthy of consideration. However, to show that ethnic groups are less at risk than people from poorer areas we would need a proper comparison of similar groups which this study clearly is not.

\section{Reference \\ 1 Cundall D, Pearson S. Inner city tuberculosis and immunisation policy. Arch Dis Child 1988;63:964-5. \\ D VICKERS \\ Royal Victoria Infirmary, Queen Victoria Road, Newcastle upon Tyne NE1 4LP}

Drs Cundall and Pearson comment:

We thank Dr Vickers for his interest in our study. We do not think that our analysis of the data was misleading. We have stated clearly that our policy of BCG immunisation of Asian infants was one of the factors which contributed to 